\section{Eco-epidemiologia dos arbovírus na área de influência da rodovia Cuiabá-Santarém (BR 163), Estado do Pará, Brasil}

\author{
Arbovirus eco-epidemiology in the area affected \\ by the Cuiabá-Santarém Highway (BR-163), \\ Pará State, Brazil
}

\author{
1 Seção de Arbovirologia \\ e Febres Hemorrágicas, \\ Instituto Evandro Chagas, \\ Belém, Brasil.

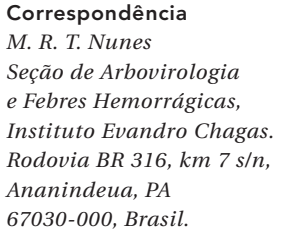

\begin{abstract}
The current study describes the eco-epidemiological aspects of arbovirus diseases in the municipalities (counties) of Novo Progresso and Trairão, Para State, Brazil, in the area affected by highway BR-163. Hemagglutination inhibition (HI) antibodies to different arboviruses were detected, with monotypic reactions to MAYV and OROV, two important arboviruses associated with epidemics in the Amazon. IgM antibodies to OROV and MAYV were found in human sera, suggesting recent infections by these viruses. Two DENV-3 strains were isolated from febrile patients in Novo Progresso and identified as genotype III strains. In general, the data suggest that the area displays ideal conditions for maintenance and circulation of arboviruses, plus a population with low immunization levels. Dynamic surveillance of local immigrants and wild animals is thus important, focusing on antibody prevalence and isolation of arboviruses, thereby allowing effective control of infections by these viral agents in the resident population along highway BR-163 in Pará State.
\end{abstract}

Environmental Monitoring; Disease Vectors; Arboviruses; Disease Outbreaks; Communicable Diseases
Marcio Roberto Teixeira Nunes 1

Taciana Fernandes Souza Barbosa 1

Livia Medeiros Neves Casseb 1

Joaquim Pinto Nunes Neto 1

Nazaré de Oliveira Segura 1

Hamilton Antônio de Oliveira Monteiro 1

Eliana Vieira Pinto 1

Samir Mansour Casseb 1

Jannifer de Oliveira Chiang 1

Lívia Caricio Martins 1

Daniele Barbosa de Almeida Medeiros 1

Pedro Fernando da Costa Vasconcelos ${ }^{1}$

\section{Introdução}

A rodovia BR 163, que liga a capital do Estado do Mato Grosso, Cuiabá, à cidade portuária de Santarém no Estado do Pará, foi inaugurada em 1973, mediante os investimentos do Programa Avança Brasil, objetivando a redução dos custos de transporte de soja do Estado do Mato Grosso para o porto de Santarém 1. Dentre os $1.764 \mathrm{~km}$ de extensão da rodovia, apenas a porção compreendida entre Cuiabá e Guarantã do Norte, no Estado do Mato Grosso, encontra-se pavimentada, sendo que o Governo Federal prevê a pavimentação de cerca de $1.000 \mathrm{~km}$ no Estado do Pará para os próximos anos.

A riqueza da biodiversidade na região reflete a coexistência de diversos biomas (florestas densas, florestas abertas, cerrados, capoeiras) e grandes áreas de transição entre floresta tropical e cerrado. Três grandes bacias hidrográficas (Rios Teles Pires-Tapajós, Rio Xingu e Rio Amazonas) drenam a região. Os recursos naturais encontrados ao longo da área de influência da rodovia BR 163 são de fundamental importância para o sustento de diferentes populações (urbanas, agricultores familiares e mais de 28 povos indígenas) em três estados brasileiros: Pará, Mato Grosso e Amazonas 1 .

O impacto ambiental inicial da construção da BR 163 corresponde a 5\% de área desmatada dentro da faixa de $50 \mathrm{~km}$ nas vizinhanças da rodovia, observando-se a conversão de floresta para 
pastagem ou agricultura, sobretudo no Estado do Mato Grosso. O que é considerado um percentual baixo quando comparado ao de outras rodovias amazônicas, que apresentam entre 26 a $58 \%$ de desmatamento 2 . No entanto, a transformação contínua de extensas áreas de florestas em pastagens e/ou monocultivos agrícolas tem acontecido ao longo da última década, levando a um importante processo de migração desordenada, bem como à fragmentação de biomas naturais da região, culminando em alterações climáticas significativas, tais como a diminuição da pluviosidade e aumento de temperatura ${ }^{3}$.

\section{Materiais e métodos}

\section{Área de estudo}

A área de influência da rodovia corresponde a 1,2 milhão km² (14,4\% do território brasileiro e $20 \%$ da Amazônia brasileira), envolvendo municípios do sudoeste do Pará, sudeste do Amazonas e norte do Mato Grosso, totalizando 71 municípios cuja economia se baseia em atividades do setor primário (agricultura, pecuária e extrativismo, extração de madeira e produção de madeirados). A área de influência da BR 163 sob jurisdição do Estado do Mato Grosso apresenta intensa produção agrícola, sobretudo de soja, enquanto que a porção do Pará destaca-se com maior área em potencial para produção florestal do Brasil. Na região, vivem comunidades tradicionais, populações urbanas e rurais e mais de 30 povos indígenas, totalizando cerca de dois milhões de habitantes. Esses fatores mostram o grande potencial econômico e a enorme diversidade biológica e social da área de abrangência da BR 1634.

O domínio do estudo eco-epidemiológico sobre arbovírus foi desenvolvido ao longo do eixo da rodovia Cuiabá-Santarém (BR 163), na qual foram escolhidos dois municípios situados no Estado do Pará: Trairão (04³4'S, 55º56'O) e Novo Progresso (0708'S, 55⒉'O). Foram realizadas três viagens para a coleta de amostras biológicas de populações humanas, bem como de vertebrados (aves, répteis, morcegos, marsupiais) e insetos hematófagos silvestres, hospedeiros e vetores em potencial de arbovírus, respectivamente. Os períodos das viagens foram baseados de acordo com a distribuição das chuvas: a primeira no período intermediário entre as estações chuvosa e seca (abril/maio), a segunda na estação de seca (agosto/setembro) e a terceira na estação chuvosa (novembro/dezembro).
Captura de vertebrados silvestres e artrópodes hematófagos

Para a captura de animais silvestres nas áreas definidas, obteve-se autorização prévia do Instituto Brasileiro do Meio Ambiente e dos Recursos Naturais Renováveis (Ibama), coordenação regional que expediu licença anual para a realização do presente estudo, observando as leis vigentes no país no que tange à captura de animais incluídos na lista de animais sob risco de extinção. Os vertebrados silvestres foram capturados utilizando redes (aves e quirópteros), armadilhas tipo Sherman (roedores de pequeno porte) e tipo Tomahawk (outros mamíferos), sendo esses, preliminarmente, identificados em bases morfológicas.

Em relação aos artrópodes hematófagos, os mesmos foram capturados utilizando armadilhas luminosas tipo CDC, durante a noite, e com o auxílio de puçás e capturadores de sucção oral (atração humana), durante o dia. As capturas foram realizadas ao nível de solo e ao de copa das árvores. Os espécimes coletados foram conservados em nitrogênio líquido $\left(-196^{\circ} \mathrm{C}\right)$ e enviados ao laboratório de entomologia da Seção de Arbovirologia e Febres Hemorrágicas do Instituto Evandro Chagas (SEARB/IEC). Após identificação, os artrópodes foram agrupados em lotes com base na data, no local de captura e na espécie, sendo encaminhados para tentativas de isolamento viral.

\section{Amostras}

Amostras de sangue total foram coletadas de humanos residentes e de animais capturados na área de estudo, obedecendo às normas vigentes de biossegurança. Para amostras humanas, cerca de 8 a 10mL de sangue foram coletadas de pacientes clinicamente suspeitos de infecção por arbovírus (indivíduos com quadro febril agudo, cefaléia, dor retro-orbitária, mialgia, exantema etc.), que procuraram, espontaneamente, os postos de saúde municipais, bem como por busca ativa em residências, objetivando a coleta em pessoas saudáveis e/ou assintomáticas. Amostras de sangue também foram coletadas de pessoas assintomáticas. Todos os participantes concordaram com os termos do estudo e assinaram o termo de livre consentimento antes das coletas de sangue.

Em relação aos animais, a coleta foi realizada obedecendo à relação entre peso do animal e volume de sangue coletado (cerca de $10 \%$ do volume sanguíneo total circulante), segundo as normas estabelecidas pelo Comitê de Ética em Pesquisa com Animais do Instituto Evandro 
Chagas (CEPAN/IEC). Eventualmente, vísceras de animais, que mostrassem sinais de doença ou fossem encontrados mortos em armadilhas e redes de captura, foram coletadas para estudos laboratoriais posteriores. Os animais convalescentes foram eutanasiados, utilizando dose letal de barbitúrico (tiopental), administrada rapidamente via endovenosa. As amostras de soro (tanto de humanos quanto de animais) foram obtidas pela centrifugação do sangue total sem anticoagulante, sendo estocadas a $-20^{\circ} \mathrm{C}$ e/ou em gelo seco até envio para os laboratórios da SEARB/IEC, objetivando a realização de tentativa de isolamento viral e testes sorológicos para diferentes arbovírus.

\section{Tentativa de isolamento}

Para as tentativas de isolamento viral, foram utilizadas: (i) amostras de sangue e soro coletadas de pacientes clinicamente suspeitos de infecção causada por arbovírus com até cinco dias de doença; (ii) amostras de sangue/soro, bem como vísceras de vertebrados silvestres; e (iii) lotes de artrópodes devidamente identificados segundo a espécie, o método de captura e local de obtenção. Todos os espécimes biológicos foram conservados em nitrogênio líquido e, posteriormente, inoculados em camundongos recém-nascidos (Mus musculus) e cultivos celulares (células C6/36 e VERO). Tanto os animais quanto as linhagens celulares inoculadas com os espécimes biológicos foram observados diariamente por, no mínimo, duas semanas ou até que sinais de doença (comprometimento do sistema nervoso central) ou efeito citopatogênico fossem detectados no caso de animais e células, respectivamente. A confirmação da presença do vírus em células infectadas foi feita pelas técnicas de imunofluorescência indireta (IFI) e fixação do complemento (FC), enquanto que, em animais, foram utilizados as técnicas de FC e o teste de neutralização (TN), conforme descrito previamente 5 .

\section{Sorologia}

\section{- Detecção de anticorpos inibidores da hemaglutinação para arbovírus}

As amostras de soros humanos, bem como de animais silvestres foram submetidas ao teste de Inibição da Hemaglutinação (IH) em micropalcas, como descrito anteriormente $5,6,7$, para a pesquisa de anticorpos contra 19 tipos de arbovírus: quatro alphavírus da família Togaviridae (vírus da encefalite eqüina do Leste-VEEE; vírus da encefalite eqüina do Oeste -VWEE; vírus Mayaro - VMAY e vírus Mucambo - VMUC); nove flaviví- rus da família Flaviviridae (vírus Ilhéus - VILH; vírus Rocio - VROC; vírus Dengue 1 - VDEN1; vírus Dengue 2 - VDEN2; vírus Dengue 3 - VDEN3; vírus Dengue 4 - VDEN4; vírus encefalite Saint Louis - VSLE; vírus da febre amarela [VFA] silvestre, cepa H111; e o VFA vacinal, cepa 17D); e seis orthobunyavírus da família Bunyaviridae (vírus Caraparu - VCAR; vírus Catu - VCATU; vírus Guaroa - VGRO; vírus Tacaiuma - VTCM; vírus Maguari - VMAG; e vírus Oropouche - VORO), sendo consideradas positivas as amostras com título recíproco $\geq 1: 20$, quando utilizadas quatro unidades de antígeno hemaglutinante.

\section{- Detecção de anticorpos IgM}

Anticorpos IgM foram pesquisados nos soros dos pacientes, conforme a técnica adaptada a partir de protocolos desenvolvidos previamente 8,9, objetivando o diagnóstico de infecções recentes para os VDEN, VFA, VMAY e VORO, cuja metodologia baseia-se na formação de imunocomplexos entre antígeno e anticorpo. As amostras positivas foram consideradas aquelas cujo valor de densidade ótica corrigida $\left(\mathrm{DO}_{405 \mathrm{~nm}}\right)$ foi superior ou igual ao valor de corte $\left(\mathrm{DO}_{405 \mathrm{~nm}}=0,200\right)$, enquanto que as amostras negativas corresponderam àquelas em que os valores de $\mathrm{DO}_{405 \mathrm{~nm}}$ foram inferiores ao valor de corte.

\section{Caracterização molecular}

\section{- Extração de RNA}

A extração do RNA viral, a partir dos fluidos celulares (VERO e/ou C6/36) infectados ou das amostras biológicas de humanos e animais silvestres, foi realizada pela técnica do Trizol LS (Invitrogen, Estados Unidos), conforme instruções do fabricante.

\section{- Detecção do genoma viral, visualização e purificação do produto amplificado}

A técnica de RT-PCR em um único tubo 10 foi utilizada para a amplificação do genoma de diferentes arbovírus, previamente isolados, usando iniciadores genéricos e degenerados (Tabela 1). Após a identificação do grupo viral mediante a utilização de iniciadores de grupo, iniciadores tipo específicos foram empregados para a obtenção de seqüências específicas, e as reações de RT-PCR foram realizadas conforme descrito por Lanciotti et al. 10 . 


\section{- Obtenção das seqüências}

O seqüenciamento nucleotídico foi realizado empregando os mesmos iniciadores utilizados na reação de RT-PCR (Tabela 1) para os vírus amplificados, bem como o kit ABI PRISM Dye Terminator (Applied Biosystems, Estados Unidos), cujas reações foram processadas em seqüenciador automático, modelo ABI PRISM 377 (Applied Biosystems, Estados Unidos), pelo emprego do método de terminação de cadeia por didesoxirribonucleotídeos marcados com substâncias fluorescentes ${ }^{11}$.

\section{- Análise das seqüências e filogenia}

As seqüências obtidas foram, inicialmente, analisadas em qualidade empregando o programa SeqMan star 5.03 (DNASTAR Inc., Madison, Estados Unidos), sendo as mesmas usadas para a montagem dos contigs utilizando o mesmo programa. Árvores filogenéticas foram construídas pelo método de Máxima Verossimilhança para seqüências completas do gene de envelope (E; 1.540 nt) do VDEN-3 utilizando diferentes modelos de substituição nucleotídica disponíveis no programa PAUP (Sinauer Associates; http://paup.csit.fsu.edu/index.html), incluindo (a) taxas de substituição códon-específicas e (b) o modelo GTR $+\mathrm{I}+\Gamma 4$, em que GTR representa a taxa de cada tipo de substituição nucleotídica relativa ao modelo geral de reversibilidade, I a proporção de sítios invariáveis e $\Gamma 4$ corresponde à forma padrão de distribuição gama estimada a partir dos dados gerados. O modelo de substituição GTR $+\mathrm{I}+\Gamma 4$ também foi usado como base para estimar árvores, empregando o método Bayesiano (Bayesian Markov chain Monte Carlo), com auxílio dos programas MrBayes (http://mrbayes. csit.fsu.edu/index.php) e BEAST (Bayesian Evolutionary Analysis Sampling Trees; http://beast. bio.ed.ac.uk). A árvore final apresentada para a análise foi estimada no programa BEAST (tamanho da cadeia $=25$ milhões, amostragem a cada mil árvores), com valores cronológicos correspondentes ao ano de emergência do vírus. As taxas de substituições nucleotídicas e a idade do ancestral comum mais recente foram estimadas, para os dados gerados, usando modelos que permitiram a determinação das taxas de variação entre linhagens, utilizando o método de relógio molecular relaxado 12 , implementado no programa BEAST. As árvores foram enraizadas com o VDEN-1 para melhorar a confiabilidade dos grupamentos filogenéticos.

\section{Resultados}

\section{Estudo da fauna de vertebrados}

Durante as três expedições de campo realizadas aos municípios de Trairão e Novo Progresso, 772 animais foram capturados; dos quais, 418 foram aves (54\%), 328, mamíferos (42,5\%), e 26, répteis $(3,5 \%)$. Entre as aves, foram identificadas, conforme a morfologia externa, cerca de 56 espécies diferentes distribuídas em 50 gêneros, 21 famílias e cinco ordens (Passeriformes, Columbiformes, Coraciiformes, Piciformes e Strigiformes). A ordem Passeriformes teve maior representatividade, apresentando 15 famílias e 47 espécies diferentes, correspondendo a 91,1\% (381 espécimes). Dentro dessa ordem, a família Thamnophilidae ( $n=97$ ) se destacou com 13 espécies, correspondendo a $23,2 \%$ do total de aves capturadas. A família Furnariidae $(\mathrm{n}=68)$ deteve 11 espécies, equivalendo a $16,5 \%$ das aves capturadas. Duas outras famílias também foram representativas, a família Thraupidae $(n=46)$, com destaque para a espécie Ramphocelus carbo $(\mathrm{n}=28)$, e a família Tyrannidae $(\mathrm{n}=15)$ com quatro espécies distintas, sendo a Mecocerculus leucophrys a mais representativa. Dentre a classe Mammalia $(\mathrm{n}=228)$, 17 espécies distintas foram identificadas e distribuídas em nove famílias e quatro ordens (Didelphimorphia, Chiroptera, Pilosa e Rodentia); das quais, a ordem Rodentia foi a mais predominante ( $\mathrm{n}=159 ; 69,7 \%$ ) com oito espécies distintas, sendo as espécies Proechymis guyannensis e Oxymycterus amazonicus as com maior número de animais, totalizando $77(33,7 \%)$ e $36(15,7 \%)$ do total de mamíferos capturados, respectivamente. A ordem Didelphimorphia ( $\mathrm{n}=28 ; 12,2 \%)$ apresentou oito espécies diferentes. A espécie mais prevalente foi a Metachirus nudicaudatus, com nove (32,14\%) espécimes. A ordem Chiroptera ( $\mathrm{n}=$ $49 ; 21,5 \%)$ teve, como representantes, morcegos das espécies Carollia perspicillata $(\mathrm{n}=43 ; 87,8 \%)$, Glossophaga soricina ( $\mathrm{n}=3 ; 6,2 \%)$, Artibeus lituratus $(\mathrm{n}=1 ; 2 \%)$ e Phyllostomus discolor $(\mathrm{n}=2$; $2 \%$ ), enquanto que a ordem Pilosa apresentou duas espécies, Bradypus tridactylus (Bradypodidae) e Choloepus didactylus (Megalonychidae). A ordem Reptilia $(n=26)$, em sua maioria, foi representada por répteis da espécie Ameiva ameiva (Teiidae), em um total de 25 animais $(96,1 \%)$, e por um único exemplar da espécie Geochelone denticulata (Testudinidae) (Tabela 2).

\section{Estudo de artrópodes hematófagos}

Em relação aos artrópodes, o total de 28.315 espécimes foram capturados, $21.018(74,2 \%)$ provenientes de Novo Progresso, e 7.297 (25,8\%), de 
Iniciadores utilizados para a amplificação de diferentes arbovírus que comumente circulam na região Amazônica brasileira.

\begin{tabular}{|c|c|c|c|c|}
\hline Família/Gênero/vírus & Iniciadores & Seqüência $\left(5^{\prime} \rightarrow 3^{\prime}\right)$ & Região & Produto \\
\hline \multirow[t]{2}{*}{ Bunyaviridae/Orthobunyavirus * } & BUNS F & AGTAGTGTACTCCAC & SRNA & \\
\hline & BUNS R & AGTAGTGTGCTCCAC & & 900 a $1000 \mathrm{nt}$ \\
\hline \multirow{2}{*}{$\begin{array}{l}\text { Bunyaviridae/Orthobunyavirus/ } \\
\text { Oropouche }\end{array}$} & ORO 1A & AGTAGTGTACTCCACTAT & & \\
\hline & ORO $2 \mathrm{~S}$ & AGTAGTGTGGCTCCACAT & SRNA & $754 \mathrm{nt}$ \\
\hline \multirow{2}{*}{$\begin{array}{l}\text { Bunyaviridae/Orthobunyavirus/sorogrupo } \\
\text { Bunyamwera }\end{array}$} & BUNW S1 & AGTAGTGTACTCCACACTA & & \\
\hline & BUNW S2 & AGTAGTGTGCTCCACCTAAAACTT & SRNA & 800 e $900 \mathrm{nt}$ \\
\hline \multirow[t]{2}{*}{ Bunyaviridae/Phlebovirus } & Ph-P-F & GGGGGGGGGGACACAAAG & & \\
\hline & Ph-P-R-RVF & GCAAAGCTGGGGTGCATCAT & SRNA & $500 \mathrm{nt}$ \\
\hline \multirow[t]{2}{*}{ Rhabdoviridae/Vesiculovirus * } & VN 55F & CCIGCMAATGARAYCCW & & \\
\hline & VN 560R & GTCARTTGYCCCCAGAARTG & Nucleoproteína & $500 \mathrm{nt}$ \\
\hline \multirow[t]{2}{*}{ Reoviridae } & Ancor primer ** & AGGTCTCGTAGACCGTGCACC & Genoma completo & NE \\
\hline & Primer (B) & GGTGCACGGTCTACGAGACCT & & \\
\hline \multirow[t]{2}{*}{ Flaviviridae/Flavivirus * } & Flav100F & AAYTCIACICAIGARATGTAY & & \\
\hline & Flav200R & CCIARCCACATRWACCA & NS5 & 800 a $1000 \mathrm{nt}$ \\
\hline \multirow[t]{2}{*}{ Flaviviridae/Flavivirus/Dengue-1 } & D1 -E237F & AGCCACACTGGTGGAAGAAC & & \\
\hline & D1-E1025R & TCATCTTGGGTCGAAAAAGG & Envelope & $789 \mathrm{nt}$ \\
\hline \multirow[t]{2}{*}{ Flaviviridae/Flavivirus/Dengue-2 } & $\mathrm{D} 2 / 1171 / \mathrm{F}$ & GAACCCAGTCTAAATGAA & & \\
\hline & D2/2023/R & TATCTTTTTCTGTTACGA & Envelope & $853 \mathrm{nt}$ \\
\hline \multirow[t]{2}{*}{ Flaviviridae/Flavivirus/Dengue-3 } & D3ENV 953F & GGAAACAGAGATTTTGTGGA & & \\
\hline & DEN3 2492R & AATTTGTATTGCTCTGTCCAGGT & Envelope & $1538 \mathrm{nt}$ \\
\hline \multirow[t]{2}{*}{ Flaviviridae/Flavivirus/Febre Amarela } & YFENV 995-1013F & GACAGGGATTTCATTGAGG & & \\
\hline & YFENV 1645-1664R & GATGATGCATCTCTCTCCAC & Envelope & $670 \mathrm{nt}$ \\
\hline \multirow[t]{2}{*}{ Togaviridae/Alphavirus * } & M2WF & YAGAGCDTTTTTCGCAYSTRGCHW & & \\
\hline & cM3WR & ACATRAANKGNGTNGTRTCRAANCCDAYCC & NS1 & $434 \mathrm{nt}$ \\
\hline \multirow[t]{2}{*}{ Togaviridae/Alphavirus/Mayaro } & MAYE2 8366F & GAAACAGTTCAAGGTCGAAG & & \\
\hline & MAY E2 9492R & GACAATGGTTGTCGTAGGAT & Envelope & $1126 \mathrm{nt}$ \\
\hline
\end{tabular}

* Iniciadores genéricos ou degenerados;

** Iniciador âncora amino-bloqueado na extremidade 3'; F: forward; R: reverso, D (A/G/T), K (G/T), N (A/C/G/T), R (A/G), V (A/C/G), W (A/T) and Y (C/T).

Trairão, e distribuídos em 241 e 631 lotes, respectivamente. Os insetos capturados foram distribuídos em três famílias: Culicidae, Psychodidae e Ceratopogonidae. Os membros da família Culicidae foram os mais prevalentes $(24.963 ; 88,2 \%)$, distribuídos em 17 gêneros e mais de 70 espécies diferentes. O gênero Culex apresentou a maioria dos mosquitos ( $\mathrm{n}=17.274$ ), dos quais, a espécie Culex (Mel.) sp. foi a mais prevalente com 13.693 $(79,2 \%)$, seguido do gênero Coquillettidia $(\mathrm{n}=$ 1.969), sendo a espécie Coquillettidia venezuelensis representada por 288 espécimes (14,6\%) (Tabela 3).

No Município de Trairão, dos 7.297 espécimes coletados, 6.771 (92,8\%) foram obtidos ao nível do solo (atração humana, $\mathrm{n}=2.795$; isca
luminosa-CDC, $\mathrm{n}=3.976)$, e 526 (7,2\%), ao nível da copa das árvores. Quanto à distribuição por período de coleta, observou-se que o maior número de espécimes capturados ocorreu no período intermediário de chuva e seca $(\mathrm{n}=3.764)$, seguido dos períodos de seca $(n=1.925)$ e chuva $(\mathrm{n}=1.607)$. Foram coletados 2.145 espécimes da família Ceratopogonidae e 700 da família Psychodidae, ambas com maior freqüência nas capturas noturnas. Em relação à família Culicidae, foram capturados 4.452 (61,\%) espécimes, cujas espécies mais freqüentes, nos três períodos de coleta, foram Wyeomyia $\mathrm{sp}$. ( $\mathrm{n}=1.558 ; 34,9 \%)$ e Culex (Mel.) sp. ( $\mathrm{n}=838 ; 18,8 \%$ ), ambas capturadas com maior freqüência no solo. Outras espécies apresentaram percentual significativo 
Tabela 2

Relação de animais capturados em Trairão e Novo Progresso na área de abrangência da rodovia BR 163, Estado do Pará, Brasil.

\begin{tabular}{|c|c|c|c|c|c|c|c|c|}
\hline Local & Classe & Ordem & Família & Gênero/Espécie & Espécimes & $\begin{array}{l}\text { Espécimes } \\
\text { (Família) }\end{array}$ & $\begin{array}{c}\text { Espécimes } \\
\text { (Ordem) }\end{array}$ & $\begin{array}{l}\text { Espécimes } \\
\text { (Classe) }\end{array}$ \\
\hline \multirow[t]{42}{*}{ Trairão } & Aves & Passeriformes & Cardinalidae & Saltator coerulescens & 3 & & & \\
\hline & & & & Habia rubica & 1 & 4 & & \\
\hline & & & Conopophagidae & Conopophaga aurita & 3 & 3 & & \\
\hline & & & Emberizidae & Arremon taciturnus & 25 & 25 & & \\
\hline & & & Formicariidae & Formicarius analis & 5 & 5 & & \\
\hline & & & Fringillidae & $\begin{array}{c}\text { Passerina cyanoides } \\
\text { cyanoides }\end{array}$ & 9 & 9 & & \\
\hline & & & Furnariidae & Automolus infuscatus & 4 & & & \\
\hline & & & & Automolus rufipileatus & 1 & & & \\
\hline & & & & Deconychura longicauda & 3 & & & \\
\hline & & & & Dendrocincla fuliginosa & 1 & & & \\
\hline & & & & Xiphorhynchus picus & 1 & & & \\
\hline & & & & Glyphorynchus spirurus & 16 & & & \\
\hline & & & & Hylexetastes perrotii & 2 & & & \\
\hline & & & & Philydor pyrrhodes & 4 & & & \\
\hline & & & & Sclerurus mexicanus & 5 & & & \\
\hline & & & & Synallaxis gujanensis & 1 & & & \\
\hline & & & & Xiphorhynchus spixii & 10 & 48 & & \\
\hline & & & Muscicapidae & Turdus fumigatus & 3 & 3 & & \\
\hline & & & Passeroidea & Geothlypis aequinoctialis & 1 & 1 & & \\
\hline & & & Pipridae & Pipra fasciicauda & 35 & 35 & & \\
\hline & & & Thamnophilidae & Thamnophilus aethiops & 3 & & & \\
\hline & & & & Thamnophilus amazonicus & 1 & & & \\
\hline & & & & Thamnomanes caesius & 8 & & & \\
\hline & & & & Taraba major & 4 & & & \\
\hline & & & & Pyriglena leuconota & 11 & & & \\
\hline & & & & Pygiptila stellaris & 1 & & & \\
\hline & & & & Phlegopsis nigromaculata & 16 & & & \\
\hline & & & & Percnostola rufifrons & 3 & & & \\
\hline & & & & Myrmotherula longipennis & 2 & & & \\
\hline & & & & Myrmoborus myotherinus & 3 & & & \\
\hline & & & & Hypocnemis cantator & 2 & & & \\
\hline & & & & Hylophylax naevia & 2 & & & \\
\hline & & & & Cercomacra nigrescens & 2 & 58 & & \\
\hline & & & Thraupidae & Ramphocelus carbo & 22 & & & \\
\hline & & & & Tachyphonus rufus & 6 & & & \\
\hline & & & & Thraupis palmarum & 2 & 30 & & \\
\hline & & & Troglodytidae & Thryothorus genibarbis & 1 & 1 & & \\
\hline & & & Tyrannidae & Mecocerculus leucophrys & 1 & & & \\
\hline & & & & Onychorhynchus coronatus & 1 & & & \\
\hline & & & & Pipra rubrocapilla & 2 & & & \\
\hline & & & & Attila spadiceus & 2 & 6 & & \\
\hline & & & Certhiidae & Microcerculus marginatus & 9 & 12 & 237 & \\
\hline
\end{tabular}

(continua) 
Tabela 2 (continuação)

\begin{tabular}{|c|c|c|c|c|c|c|c|c|}
\hline Local & Classe & Ordem & Família & Gênero/Espécie & Espécimes & $\begin{array}{l}\text { Espécimes } \\
\text { (Família) }\end{array}$ & $\begin{array}{l}\text { Espécimes } \\
\text { (Ordem) }\end{array}$ & $\begin{array}{c}\text { Espécimes } \\
\text { (Classe) }\end{array}$ \\
\hline \multirow[t]{24}{*}{ Trairão } & Aves & $\begin{array}{l}\text { Columbifor- } \\
\text { mes }\end{array}$ & Columbidae & Leptotila rufaxilla & 1 & 1 & & \\
\hline & & & & Columbina passerina & 2 & 2 & & \\
\hline & & & & Geotrygon montana & 3 & & & \\
\hline & & & & Geotrygon violacea & 2 & 5 & 8 & \\
\hline & & Coraciiformes & Momotidae & Momotus momota & 2 & 2 & & \\
\hline & & & Chloroceryle & Chloroceryle inda & 1 & 1 & 3 & \\
\hline & & Piciformes & Picidae & Dryocopus lineatus & 1 & 1 & & \\
\hline & & & Bucconidae & Malacoptila rufa & 5 & 5 & 6 & \\
\hline & & Strigiformes & Strigidae & Glaucidium brasilianum & 2 & 2 & 2 & 256 \\
\hline & Mammalia & $\begin{array}{l}\text { Didelphimor- } \\
\text { phia }\end{array}$ & Didelphidae & Metachirus nudicaudatus & 3 & & & \\
\hline & & & & Philander opossum & 2 & & & \\
\hline & & & & Didelphis albiventris & 4 & 9 & & \\
\hline & & & Caluromyidae & Caluromys phylander & 1 & 1 & 10 & \\
\hline & & Chiroptera & Phyllostomidae & Carollia perspicillata & 20 & & & \\
\hline & & & & Glossophaga soricina & 3 & & & \\
\hline & & & & Phyllostomus discolor & 1 & 24 & 24 & \\
\hline & & Pilosa & Bradypodidae & Bradypus tridactylus & 1 & 1 & & \\
\hline & & & Megalonychidae & Choloepus didactylus & 1 & 1 & 2 & \\
\hline & & Rodentia & $?$ & Proechymis guyanensis & 5 & 5 & & \\
\hline & & & Cricetidae & Oryzomys goeldi & 10 & & & \\
\hline & & & & Nectomis squamipes & 15 & 25 & & \\
\hline & & & Caluromyidae & Caluromys phylander & 15 & 15 & & \\
\hline & & & Muridae & Rattus rattus & 3 & 3 & 48 & 84 \\
\hline & Reptilia & Squamata & Teiidae & Ameiva ameiva & 6 & 6 & 6 & 6 \\
\hline \multirow{16}{*}{$\begin{array}{c}\text { Novo } \\
\text { Progresso }\end{array}$} & Aves & Passeriformes & Cardinalidae & Saltator maximus & 5 & & & \\
\hline & & & & Habia rubica & 2 & 7 & & \\
\hline & & & Emberizidae & Arremon taciturnus & 1 & & & \\
\hline & & & & Sporophila caerulescens & 10 & & & \\
\hline & & & & Oryzoborus angolensis & 8 & 19 & & \\
\hline & & & Furnariidae & Automolus infuscatus & 3 & & & \\
\hline & & & & Automolus rufipileatus & 1 & & & \\
\hline & & & & Deconychura longicauda & 1 & & & \\
\hline & & & & Dendrocincla fuliginosa & 4 & & & \\
\hline & & & & Xiphorhynchus picus & 2 & & & \\
\hline & & & & Glyphorynchus spirurus & 1 & & & \\
\hline & & & & Hylexetastes perrotii & 1 & & & \\
\hline & & & & Philydor pyrrhodes & 3 & & & \\
\hline & & & & Sclerurus mexicanus & 1 & & & \\
\hline & & & & Synallaxis gujanensis & 2 & & & \\
\hline & & & & Xiphorhynchus spixii & 1 & 20 & & \\
\hline
\end{tabular}

(continua) 
Tabela 2 (continuação)

\begin{tabular}{|c|c|c|c|c|c|c|c|c|}
\hline Local & Classe & Ordem & Família & Gênero/Espécie & Espécimes & $\begin{array}{l}\text { Espécimes } \\
\text { (Família) }\end{array}$ & $\begin{array}{l}\text { Espécimes } \\
\text { (Ordem) }\end{array}$ & $\begin{array}{l}\text { Espécimes } \\
\text { (Classe) }\end{array}$ \\
\hline \multirow{42}{*}{$\begin{array}{l}\text { Novo } \\
\text { Progresso }\end{array}$} & Aves & Passeriformes & Thamnophilidae & Thamnophilus aethiops & 2 & & & \\
\hline & & & & Thamnophilus amazonicus & 3 & & & \\
\hline & & & & Thamnomanes caesius & 5 & & & \\
\hline & & & & Taraba major & 2 & & & \\
\hline & & & & Pyriglena leuconota & 7 & & & \\
\hline & & & & Pygiptila stellaris & 9 & & & \\
\hline & & & & Myrmoborus myotherinus & 1 & & & \\
\hline & & & & Hypocnemis cantator & 2 & & & \\
\hline & & & & Hylophylax naevia & 3 & & & \\
\hline & & & & Cercomacra nigrescens & 5 & 39 & & \\
\hline & & & Thraupidae & Ramphocelus carbo & 6 & & & \\
\hline & & & & Tachyphonus rufus & 3 & & & \\
\hline & & & & Thraupis palmarum & 4 & & & \\
\hline & & & & Thraupis episcopus & 3 & 16 & & \\
\hline & & & Tyrannidae & Mecocerculus leucophrys & 4 & & & \\
\hline & & & & Onychorhynchus coronatus & 3 & & & \\
\hline & & & & Pipra rubrocapilla & 1 & & & \\
\hline & & & & Attila spadiceus & 1 & 9 & & \\
\hline & & & Certhiidae & Microcerculus marginatus & 1 & & & \\
\hline & & & Muscicapidae & Turdus fumigatus & 3 & & & \\
\hline & & & Conopophagidae & Conopophaga aurita & 3 & & & \\
\hline & & & Formicariidae & Formicarius analis & 2 & & & \\
\hline & & & Icteridae & Cacicus cela & 5 & & & \\
\hline & & & Passeroidea & Geothlypis aequinoctialis & 1 & & & \\
\hline & & & Pipridae & Pipra fasciicauda & 15 & & & \\
\hline & & & Certhiidae & Microcerculus marginatus & 1 & & & \\
\hline & & & Fringillidae & $\begin{array}{c}\text { Passerina cyanoides } \\
\text { cyanoides }\end{array}$ & 1 & & & \\
\hline & & & Troglodytidae & Thryothorus genibarbis & 2 & & 144 & \\
\hline & & $\begin{array}{l}\text { Columbifor- } \\
\text { mes }\end{array}$ & Columbidae & Leptotila rufaxilla & 8 & & & \\
\hline & & & & Columbina passerina & 3 & & & \\
\hline & & & & Geotrygon montana & 2 & & & \\
\hline & & & & Geotrygon violacea & 3 & 16 & 16 & \\
\hline & & Piciformes & Bucconidae & Malacoptila rufa & 2 & 2 & 2 & 162 \\
\hline & Mammalia & $\begin{array}{l}\text { Didelphimor- } \\
\text { phia }\end{array}$ & Caluromyidae & Caluromys phylander & 1 & 1 & & \\
\hline & & & Didelphinae & Monodelphis americana & 4 & & & \\
\hline & & & & Marmosa cinerea & 3 & & & \\
\hline & & & & Didelphis marsupialis & 4 & & & \\
\hline & & & & Metachirus nudicaudatus & 6 & 17 & 18 & \\
\hline & & Rodentia & Cricetidae & Oxymycterus amazonicus & 86 & & & \\
\hline & & & & Neacomys guianae & 1 & 87 & & \\
\hline & & & Echimyidae & Proechymis guyanensis & 122 & & & \\
\hline & & & & Proechimys longicaudatus & 2 & 124 & 211 & \\
\hline
\end{tabular}

(continua) 
Tabela 2 (continuação)

\begin{tabular}{|c|c|c|c|c|c|c|c|c|}
\hline Local & Classe & Ordem & Família & Gênero/Espécie & Espécimes & $\begin{array}{l}\text { Espécimes } \\
\text { (Família) }\end{array}$ & $\begin{array}{c}\text { Espécimes } \\
\text { (Ordem) }\end{array}$ & $\begin{array}{c}\text { Espécimes } \\
\text { (Classe) }\end{array}$ \\
\hline \multirow{5}{*}{$\begin{array}{c}\text { Novo } \\
\text { Progresso }\end{array}$} & Mammalia & Chiroptera & Phyllostomidae & Carollia perspicillata & 14 & & & \\
\hline & & & & Phyllostomus discolor & 1 & & & \\
\hline & & & & Artibeus lituratus & 1 & 15 & 15 & 244 \\
\hline & Reptilia & Squamata & Teiidae & Ameiva ameiva & 19 & & & \\
\hline & & Testudines & Testudinidae & Geochelone denticulata & 1 & 20 & & 20 \\
\hline Total & & & & & & & & 772 \\
\hline
\end{tabular}

?: não identificado.

Tabela 3

Artrópodes hematófagos capturados nos sítios de estudo ao longo da área de abrangência da rodovia BR 163, Estado do Pará, Brasil.

\begin{tabular}{|c|c|c|c|c|c|c|}
\hline Localidade & Família & $\begin{array}{l}\text { Gênero ou } \\
\text { subfamília }\end{array}$ & Espécie & Espécimes & Total (Família) & Total (localidade) \\
\hline \multirow[t]{29}{*}{ Trairão } & Culicidae & Anopheles & Anopheles mediopunctatus & 1 & & \\
\hline & & & Anopheles nimbus & 2 & & \\
\hline & & & Anopheles oswaldoi & 2 & & \\
\hline & & & Anopheles (Anopheles) sp. & 2 & & \\
\hline & & & Anopheles (Nyssorhynchus) sp. & 55 & & \\
\hline & & Coquillettidia & Coquillettidia (Rhy.) arribazagae & 120 & & \\
\hline & & & Coquillettidia albicosta & 3 & & \\
\hline & & & Coquillettidia (Rhynchotaenia) sp. & 124 & & \\
\hline & & & Coquillettidia lynchi & 96 & & \\
\hline & & & Coquillettidia venezuelensis & 288 & & \\
\hline & & Culex & Culex (Carrollia) sp. & 7 & & \\
\hline & & & Culex coronator & 32 & & \\
\hline & & & Culex declarator & 8 & & \\
\hline & & & Culex (Culex) sp. & 106 & & \\
\hline & & & Culex (Melanoconion) sp. & 838 & & \\
\hline & & Haemagogus & Haemagogus leucocelaenus & 3 & & \\
\hline & & & Haemagogus janthinomys & 118 & & \\
\hline & & Johnbelkinia & Johnbelkinia longipes & 21 & & \\
\hline & & Limatus & Limatus sp. & 34 & & \\
\hline & & & Limatus durhamii & 35 & & \\
\hline & & & Limatus flavisetosus & 46 & & \\
\hline & & Mansonia & Mansonia humeralis & 4 & & \\
\hline & & & Mansonia (Mansonia) sp. & 3 & & \\
\hline & & Ochlerotatus & Ochlerotatus hastatus & 1 & & \\
\hline & & & Ochlerotatus hortator & 2 & & \\
\hline & & & Ochlerotatus scapularis & 1 & & \\
\hline & & & Ochlerotatus serratus & 13 & & \\
\hline & & & Ochlerotatus (Howardina) sp. & 1 & & \\
\hline & & Phoniomyia & Phoniomyia sp. & 5 & & \\
\hline
\end{tabular}

(continua) 
Tabele 3 (continuação)

\begin{tabular}{|c|c|c|c|c|c|c|}
\hline Localidade & Família & $\begin{array}{l}\text { Gênero ou } \\
\text { subfamília }\end{array}$ & Espécie & Espécimes & Total (Família) & Total (localidade) \\
\hline \multirow[t]{22}{*}{ Trairão } & Culicidae & Psorophora & Psorophora albipes & 14 & & \\
\hline & & & Psorophora cingulata & 5 & & \\
\hline & & & Psorophora ferox & 3 & & \\
\hline & & & Psorophora lutzii & 3 & & \\
\hline & & Sabethes & Sabethes belisarioi & 131 & & \\
\hline & & & Sabethes cyaneus & 20 & & \\
\hline & & & Sabethes chloropterus & 41 & & \\
\hline & & & Sabethes forattinii & 4 & & \\
\hline & & & Sabethes glaucodaemon & 75 & & \\
\hline & & & Sabethes quasicyaneus & 18 & & \\
\hline & & & Sabethes tarsopus & 56 & & \\
\hline & & & Sabethes (Sabethes) sp. & 32 & & \\
\hline & & & Sabethes intermedius & 1 & & \\
\hline & & Trichoprosopon & Trichoprosopon digitatum & 117 & & \\
\hline & & Uranotaenia & Uranotaenia calosomata & 22 & & \\
\hline & & & Uranotaenia (Uranotaenia) sp. & 206 & & \\
\hline & & & Uranotaenia geometrica & 83 & & \\
\hline & & & Uranotaenia hystera & 11 & & \\
\hline & & Wyeomyia & Wyeomyia melanocephala & 81 & & \\
\hline & & & Wyeomyia sp. & 1.558 & 4.452 & \\
\hline & Ceratopogonidae & Culicoides & Culicoides paraensis & 2.145 & 2.145 & \\
\hline & Psychodidae & Phlebotominae & Flebótomos & 700 & 700 & 7.297 \\
\hline \multirow[t]{21}{*}{ Novo Progresso } & Culicidae & Aedeomyia & Aedeomyia squamipennis & 3 & & \\
\hline & & Anopheles & Anopheles mediopunctatus & 7 & & \\
\hline & & & Anopheles (Anopheles) sp. & 1 & & \\
\hline & & & Anopheles nimbus & 1 & & \\
\hline & & & Anopheles nuneztovari & 1 & & \\
\hline & & & Anopheles oswaldoi & 13 & & \\
\hline & & & Anopheles triannulatus & 306 & & \\
\hline & & & Anopheles (Nyssorhynchus) sp. & 382 & & \\
\hline & & Coquillettidia & Coquillettidia albicosta & 242 & & \\
\hline & & & Coquillettidia (Rhynchotaenia) sp. & 227 & & \\
\hline & & & Coquillettidia alynchi & 59 & & \\
\hline & & & Coquillettidia venezuelensis & 810 & & \\
\hline & & Culex & Culex (Carrollia) sp. & 3 & & \\
\hline & & & Culex coronator & 610 & & \\
\hline & & & Culex declarator & 1 & & \\
\hline & & & Culex pedroi & 24 & & \\
\hline & & & Culex (Culex) sp. & 1.945 & & \\
\hline & & & Culex (Melanoconion) sp. & 13.693 & & \\
\hline & & & Culex spissipes & 7 & & \\
\hline & & Haemagogus & Haemagogus leucocelaenus & 4 & & \\
\hline & & & Haemagogus janthinomys & 100 & & \\
\hline
\end{tabular}

(continua) 
Tabele 3 (continuação)

\begin{tabular}{|c|c|c|c|c|c|c|}
\hline Localidade & Família & $\begin{array}{l}\text { Gênero ou } \\
\text { subfamília }\end{array}$ & Espécie & Espécimes & Total (Família) & Total (localidade) \\
\hline \multirow[t]{31}{*}{ Novo Progresso } & Culicidae & Johnbelkinia & Johnbelkinia longipes & 6 & & \\
\hline & & Limatus & Limatus sp. & 15 & & \\
\hline & & & Limatus durhamii & 18 & & \\
\hline & & & Limatus flavisetosus & 10 & & \\
\hline & & Mansonia & Mansonia titillans & 6 & & \\
\hline & & & Mansonia pseudotitillans & 52 & & \\
\hline & & & Mansonia (Mansonia) sp. & 163 & & \\
\hline & & & Mansonia argyrothorax & 1 & & \\
\hline & & Ochlerotatus & Ochlerotatus fulvus & 2 & & \\
\hline & & & Ochlerotatus scapularis & 28 & & \\
\hline & & & Ochlerotatus serratus & 66 & & \\
\hline & & & Ochlerotatus (Howardina) sp. & 7 & & \\
\hline & & Orthopodomyia & Orthopodomyia fascipes & 1 & & \\
\hline & & Psorophora & Psorophora albipes & 730 & & \\
\hline & & & Psorophora cingulata & 187 & & \\
\hline & & & Psorophora ferox & 40 & & \\
\hline & & & Psorophora lutzii & 7 & & \\
\hline & & & Psorophora (Janthinosoma) sp. & 13 & & \\
\hline & & Sabethes & Sabethes cyaneus & 7 & & \\
\hline & & & Sabethes chloropterus & 12 & & \\
\hline & & & Sabethes quasicyaneus & 7 & & \\
\hline & & & Sabethes tarsopus & 3 & & \\
\hline & & Trichoprosopon & Trichoprosopon digitatum & 18 & & \\
\hline & & Uranotaenia & Uranotaenia calosomata & 10 & & \\
\hline & & & Uranotaenia (Uranotaenia) sp. & 93 & & \\
\hline & & & Uranotaenia geométrica & 1 & & \\
\hline & & Wyeomyia & Uranotaenia hystera & 11 & & \\
\hline & & & Wyeomyia melanocephala & 18 & & \\
\hline & & & Wyeomyia sp. & 540 & 20.511 & \\
\hline & Ceratopogonidae & Culicoides & Culicoides paraensis & 36 & 36 & \\
\hline & Psychodidae & Phlebotominae & Flebótomos & 471 & 471 & 21.018 \\
\hline Total & & & & & & 28.315 \\
\hline
\end{tabular}

de captura em, pelo menos, um dos períodos de coleta específicos, tais como: Haemagogus (Hag) janthinomys ( $\mathrm{n}=118 ; 2,6 \%)$ no período intermediário; C. (Rhy) venezuelensis $(\mathrm{n}=288 ; 6,5 \%) \mathrm{e}$ Uranotaenia (Ura) sp. $(\mathrm{n}=206 ; 4,6 \%)$ no período de seca; e Coquillettidia (Rhy) arribazagae (n = 120; 2,7\%) no período chuvoso (Tabela 3 ).

Em relação ao Município de Novo Progresso, dos 21.018 artrópodes coletados, 20.755 (98,7\%) foram obtidos em coletas diurnas ao nível do solo (atração humana, $\mathrm{n}=2.700$ ) e noturnas (isca luminosa-CDC, $\mathrm{n}=18.055)$, e apenas 269 (0,3\%), na copa das árvores (período diurno). A maior freqüência de captura foi durante o período chuvoso ( $\mathrm{n}=12.549 ; 59,7 \%$ ). O maior número de espécimes coletados foi pertencente à família Culicidae ( $n=20.511 ; 97,5 \%$ ), seguido das famílias Psychodidae ( $\mathrm{n}=471 ; 2,2 \%$ ) e Ceratopogonidae ( $n=36 ; 0,3 \%$ ), capturados com maior freqüência em coletas noturnas. Na família Culicidae, destacaram-se as espécies Culex (Mel.) sp. ( $\mathrm{n}=13.693$; 65,14\%) e Culex (Cux.) sp. ( $\mathrm{n}=1.945 ; 9,2 \%)$ por apresentarem percentuais de capturas significativos nos três períodos de coleta, além das es- 
pécies Anopheles (Nys.) triannulatus, Anopheles (Nys.) sp., Coquillettidia (Rhy) albicosta, Coquillettidia (Rhy) sp., C. (Rhy) venezuelensis, Culex (Cux.) coronator, Mansonia (Man.) sp., Psorophora (Jan.) albipes, Psorophora (Gra.) cingulata e Wyeomyia sp., as quais foram capturadas em, pelo menos, um dos períodos de coleta (Tabela 3).

\section{Prevalência de anticorpos para arbovírus em humanos}

Quanto aos humanos, o total de 1.398 soros de indivíduos residentes em Novo Progresso $(n=744)$ e Trairão ( $n=654$ ) foram coletados; dos quais, 536 soros $(38,3 \%)$ foram obtidos durante o período intermediário de chuva e seca; 405 (28,9\%), durante a estação de seca; e 427 (32,8\%), ao longo da estação chuvosa.

Em relação à prevalência de anticorpos IH na população humana estudada, anticorpos IH foram detectados para diversos arbovírus pertencentes aos gêneros Flavivirus, Alphavirus e Orthobunyavirus, principalmente em indivíduos do sexo feminino entre a faixa etária de 30 a 40 anos. Em 298 (23,3\%) das 1.398 amostras, foram encontrados anticorpos para arbovírus do gênero Flavivirus, sendo 165 (55,3\%) de Novo Progresso e 133 (44,7\%) de Trairão. Dessas, dez amostras corresponderam a indivíduos que apresentaram reações monotípicas para, pelo menos, um dos sorotipos do VDEN, 31 para VFA vacinal e um para o VSLE (Figura 1a). Não se observou correlação estatística significante $\left(\chi^{2}=1,512 ; p=0,4532\right)$ entre positividade para anticorpos anti-flavivírus e os períodos de coleta. Vinte e quatro indivíduos apresentaram anticorpos contra vírus do gênero Orthobunyavirus, dos quais, $83,3 \%$ procederam do Município de Trairão (Figura 1b), sendo observadas reações monotípicas para os VORO, VMAG, VGRO, VTCM, VCATU e VCAR. Dentre os alphavírus, 79 reações tipo específicas foram observadas para o VMAY, quatro para o VMUC, três para o VEEE e cinco para VWEE em ambos os municípios (Figura 1c). Observou-se que, tanto em Novo Progresso quanto em Trairão, um maior número de pessoas apresentaram anticorpos $\mathrm{IH}$ para os VMAY e VORO nos períodos intermediário e estação chuvosa (Figura 1d).

No que tange à detecção de anticorpos IgM em amostras IH positivas para flavivírus coletadas nos dois municípios paraenses incluídos no estudo, 19 foram IgM positivas para dengue. Dessas, dez foram procedentes de Novo Progresso $(52,6 \%)$ e nove de Trairão $(47,4 \%)$, todas coletadas no período intermediário de chuvas. Dentre as amostras que apresentaram reação monotípica para oVMAY $(\mathrm{n}=78), 10(12,8 \%)$ apresentaram anticorpos da classe IgM anti-VMAY, sendo seis procedentes de Novo Progresso e quatro de Trairão. Das amostras de Trairão que apresentaram reação monotípica para o VORO no IH (n = 35), apenas uma $(2,8 \%)$ apresentou anticorpo IgM anti-VORO.

Prevalência de anticorpos para arbovírus em animais silvestres

Das 181 amostras de soro de animais silvestres testadas (aves, mamíferos e répteis), 85 (46,9\%) foram procedentes de Novo Progresso e 96 (53,1\%) de Trairão. Dessas, amostras obtidas de dois répteis (A. ameiva) capturados em Novo Progresso foram $\mathrm{IH}$ positivas, sendo uma delas positiva para o VSLE e VCAR e a outra apresentando reação cruzada para flavivírus. Três amostras de aves (Phlegopsis nigromaculata) apresentaram reação monotípica para o VSLE. Das amostras coletadas em Trairão, cinco soros obtidos de aves apresentaram reações monotípicas para arbovírus, sendo uma da espécie Pyriglena leuconota (IH positivo para VWEE), uma ave da espécie P. nigromaculata (IH positivo para o VCAR e três aves IH positivas para o VSLE - duas aves da espécie $P$. nigromaculata e uma da espécie $G e$ otrygon montana). Anticorpos IgM anti-VDEN, anti-VFA, anti-VMAY e anti-VORO não foram detectados.

\section{Isolamento viral e obtenção de seqüências nucleotídicas}

Das amostras submetidas à tentativa de isolamento viral, apenas dois soros humanos coletados em Novo Progresso (H 704898 e H 704785) foram positivos, sendo os vírus identificados como VDEN3 pelo teste de IFI. Os isolamentos virais foram confirmados pelo teste de RT-PCR. As cepas isoladas foram amplificadas, inicialmente, com iniciadores genéricos Flav 100F e Flav 200R e, posteriormente, com iniciadores específicos para o VDEN3 (Tabela 1), sendo obtidas seqüências completas do gene de envelope das mesmas correspondendo a um produto com $1.543 \mathrm{nt}$.

\section{Análise das seqüências e filogenia}

A análise das seqüências completas do gene E das duas cepas revelou alto grau de homologia entre si e com outras cepas do VDEN3 (98,7\%) isoladas de diferentes regiões do Brasil, das Américas e do mundo, sendo que as cepas estudadas foram identificadas como membros do genótipo III, mais conhecido como genótipo do subcontinente indiano, comumente encontrado no Brasil. A análise Bayesiana subdividiu as amostras em quatro grupos principais, identificadas como 
Figura 1

Distribuição das amostras que apresentaram anticorpos anti-flavivírus com relação ao período de coleta e município de procedência (1a); Distribuição das amostras que apresentaram anticorpos anti-orthobunyavirus por município (1b); Distribuição das amostras que apresentaram anticorpos anti-alphavirus por município (1c); Distribuição das amostras positivas para os VORO e VMAY, segundo o município de origem e período de coleta das amostras (1d).

1a)

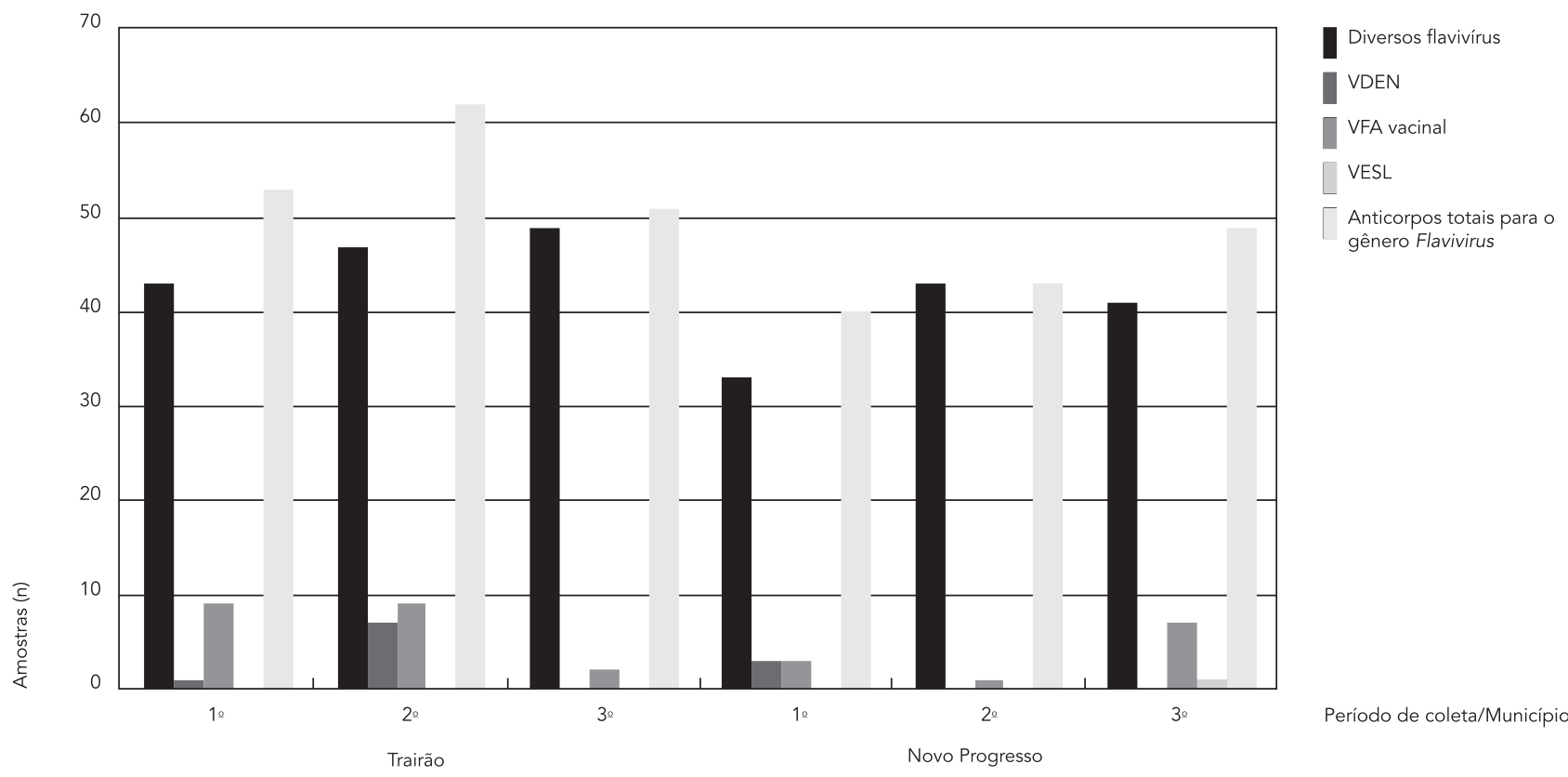

1b)

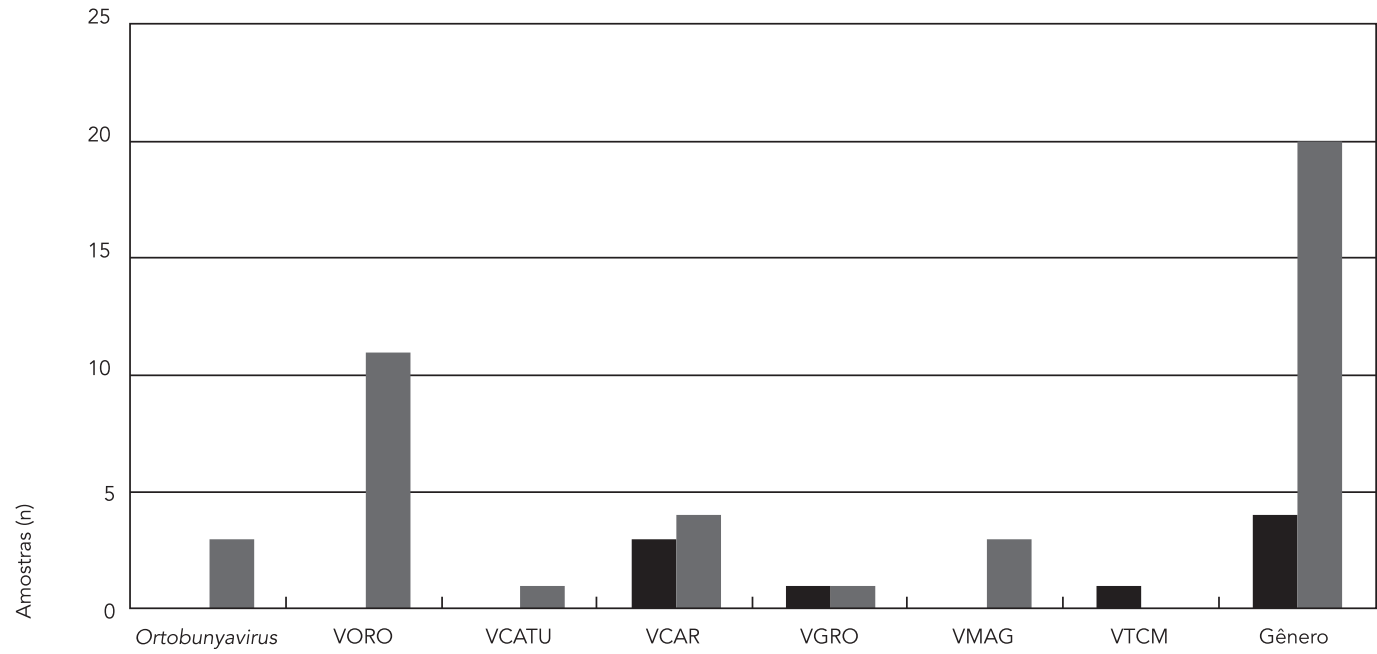


Figura 1 (continuação)

1c)

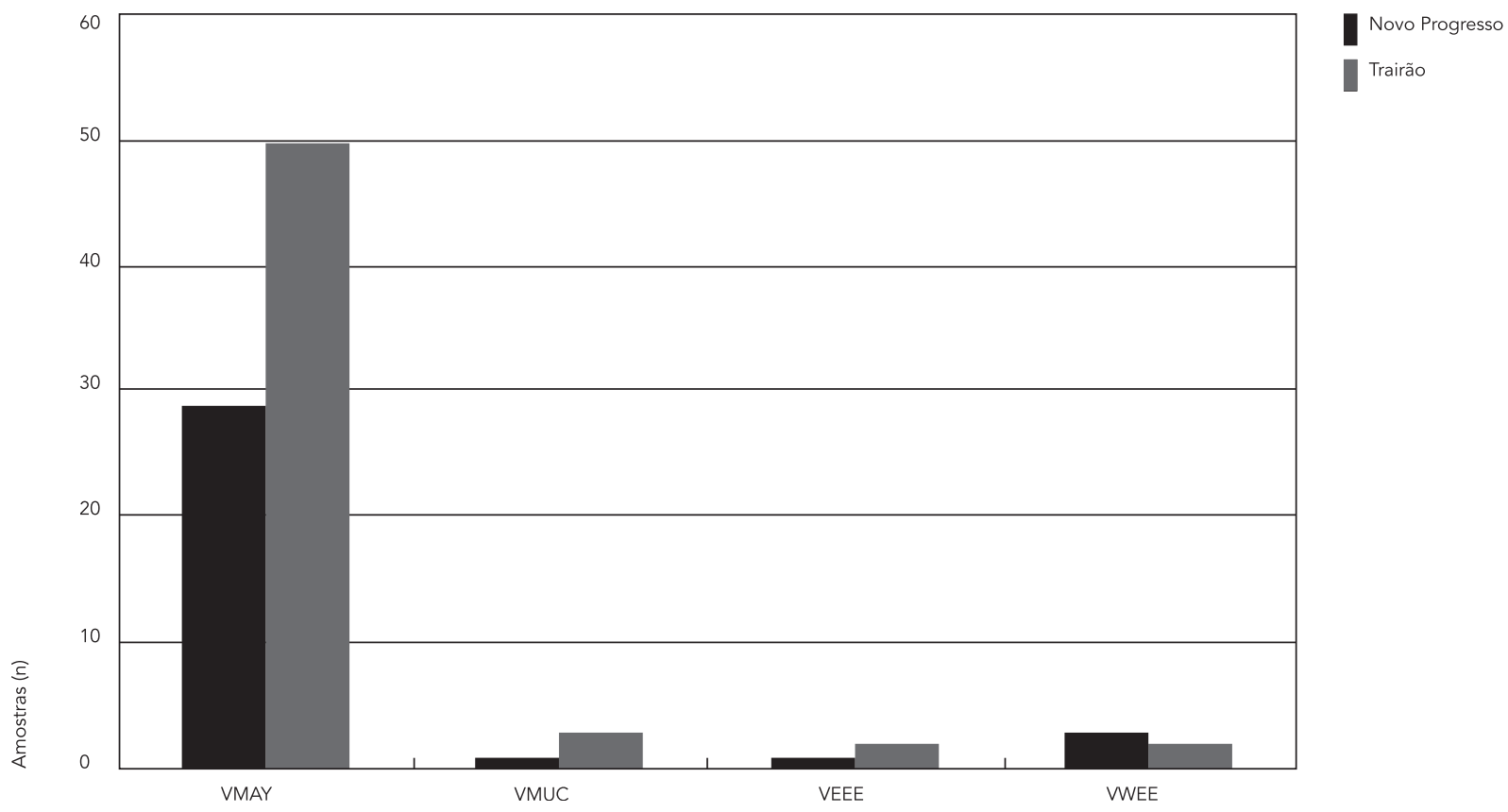

$1 d)$

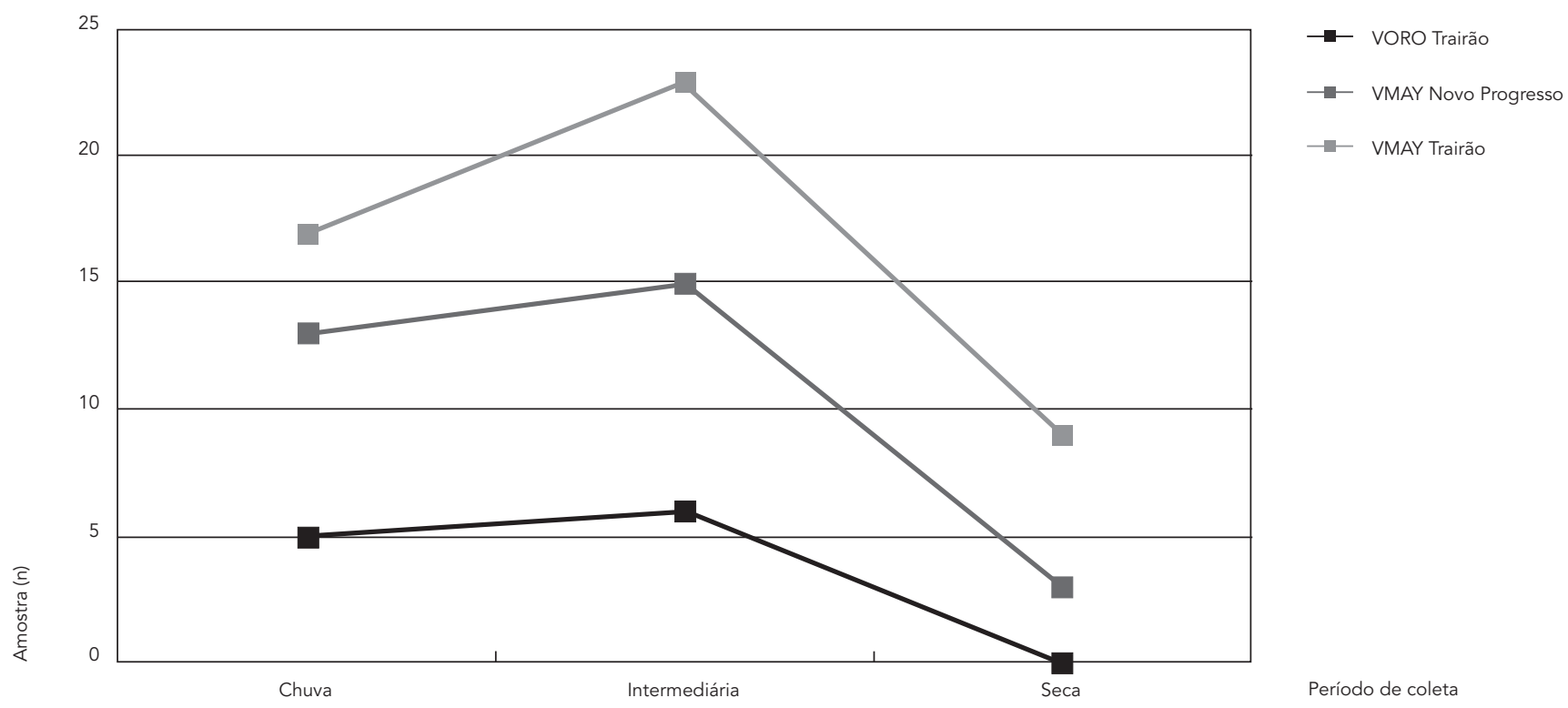

Nota: 1ạ coleta no período intermediário de chuva; 2ạ coleta durante a estação de seca; 3ạ coleta durante a estação chuvosa.

* Anticorpos totais anti-orthobunyavirus.

VDEN: vírus Dengue; VFA: vírus da febre amarela; VESL: vírus encefalite Saint Louis; VORO: vírus Oropouche; VCATU: vírus Catu; VCAR: vírus Caraparu; VGRO: vírus Guaroa; VMAG: vírus Maguari; VTCM: vírus Tacaiuma; VMAY: vírus Mayaro; VMUC: vírus Mucambo; VEEE: vírus da encefalite eqüina do Leste; VWEE: vírus da encefalite eqüina do Oeste. 
genótipos (I a IV). Dentro do grupo de interesse (genótipo III), sete subclades foram formadas (III-a, III-b, III-c, III-d, III-e, III-f e III-g), sendo as cepas de Novo Progresso incluídas na subclade III-c e geneticamente mais relacionadas às cepas isoladas em Belém durante a epidemia ocorrida em 2008 (Figura 2). A subclade III-a incluiu cepas de outras localidades do Brasil (Nordeste, Centro-Oeste e Sudeste brasileiros), cepas isoladas de outros municípios do Estado do Pará (Igarapé Açu, Parauapebas e Santarém), bem como cepas isoladas no Paraguai, no ano de 2003. A subclade III-b agrupou uma cepa de Roraima, isolada em 2002, e cepas das ilhas de Martinica e Cuba, isoladas em 2000. As subclades III-d e III-e agruparam, respectivamente, cepas exclusivamente dos Estados de Roraima e Rondônia, isoladas durante o ano de 2005. As cepas venezuelanas foram agrupadas juntamente com uma cepa do México na subclade III-f, enquanto que as cepas isoladas no subcontinente indiano (Sri Lanka, Samoa e Índia) foram incluídas na subclade III-g.

A aplicação do método de relógio molecular permitiu verificar o período de emergência das cepas em estudo, levando em consideração a taxa média de substituição nucleotídica por sítio e por ano calculada em $4 \times 10^{-4}$, estando a mesma dentro do valor observado para outros flavivírus 13 . Em relação às cepas paraenses isoladas em Novo Progresso no ano de 2005, estimou-se a data de emergência em 5,2 anos e sua associação evolutiva com as cepas do VDEN-3 que circularam em Roraima e Rondônia no mesmo ano, bem como na Venezuela e no México entre os anos de 2000 e 2001, cujos períodos médios de emergência foram estimados em 10,5 ( $\pm 4,2)$ anos (Figura 2).

\section{Discussão}

A região amazônica brasileira, dentro de sua vasta abrangência territorial, apresenta uma enorme biodiversidade ainda pouco conhecida. Nesse ambiente complexo, coabitam inúmeras espécies de vertebrados silvestres e de artrópodes hematófagos que servem como hospedeiros e vetores, respectivamente, para muitos agentes patogênicos, dentre os quais, os arbovírus assumem grande importância em saúde pública na região 14,15. A ação antrópica indiscriminada desse ecossistema tem provocado, ao longo dos anos, o surgimento de várias arboviroses e de outras doenças virais. Durante o período de 1954 a 2006, foi possível o isolamento de, pelo menos, 196 tipos diferentes de arbovírus, dos quais, 160 foram isolados, pela primeira vez, no Brasil (principalmente na Amazônia brasileira), com, pelo menos, 100 tipos novos para o mundo 16 .
O crescimento populacional, a urbanização desordenada e o desflorestamento produzem sérios impactos ambientais, levando ao desequilíbrio do ecossistema, muitas vezes de forma irreversível. Este desequilíbrio ambiental observado durante a abertura e asfaltamento de importantes rodovias na Amazônia (Belém-Brasília, Transamazônica e PA 150), e que vem sendo registrado ao longo da rodovia Cuiabá-Santarém (BR 163), pode proporcionar a emergência de diferentes arbovírus, tornando possível o contato direto do homem com esses agentes 17,18.

No Brasil, cerca de 36 arbovírus têm sido associados à doença humana, alguns, inclusive, ocasionando quadros graves que podem levar à morte 14,17,18,19. Desses, cinco são de grande importância em termos de saúde pública, pois estão associados com epidemias, quais sejam: VDEN, VORO, VMAY, VROC e VFA. Os VDEN e VORO encontram-se associados a epidemias em áreas urbanas, enquanto que os VMAY, VROC e VFA à doença humana em áreas silvestres 20. Assim, a investigação eco-epidemiológica das arboviroses na área da BR 163 é de grande importância para verificar fatores possivelmente associados à emergência e/ou reemergência de arbovírus patogênicos ao homem.

Entre os artrópodes, um grande número de insetos hematófagos foram identificados como potenciais transmissores de arbovírus, principalmente aqueles pertencentes às famílias Culicidae, Ceratopogonidae e Psychodidae. Dentre os espécimes capturados e identificados como membros da família Culicidae, muitos têm sido associados a isolamentos de arbovírus, bem como à transmissão em natureza desses agentes virais, como no caso do gênero Coquillettidia com as espécies Coquillettidia arribazagae e Coquillettidia lynchi, das quais, o vírus Una (Togaviridae, Alphavirus) e o vírus Oriboca (VORI) e vírus Wyeomyia (VWYE), família Bunyaviridae do gênero Orthobunyavirus, têm sido isolados, respectivamente. Outra espécie do gênero ( $C$. venezuelensis) também tem sido associada com isolamentos e transmissão de diferentes arbovírus dos gêneros Flavivirus (VBSQ), Orthobunyavirus (VGMA, VCATU, VORI, VORO e vírus Moju [VMOJ]), Alphavirus (VMUC) e o vírus Itaporanga [VITP] um membro do gênero Phlebovirus 21.

Mosquitos do gênero Culex, que foram os espécimes mais prevalentes principalmente no Município de Novo Progresso, são reconhecidos como vetores de diferentes arbovírus, tais como Culex pedroi (vírus Ananindeua - VANA, vírus Capim - VCAP, VEEE, VWEE, VGMA, VORI, vírus Itaqui - VITQ), Culex coronator (VSLE, VCAR, e VTUC), e Culex declarator (VSLE, VMOJ, Turlock [VTUR], VBSQ e VCATU). Outras espécies de 
Figura 2

Árvore filogenética construída pelo método Bayesiano para as cepas do VDEN-3 isoladas no Município de Novo Progresso, Pará, Brasil, em 2005.

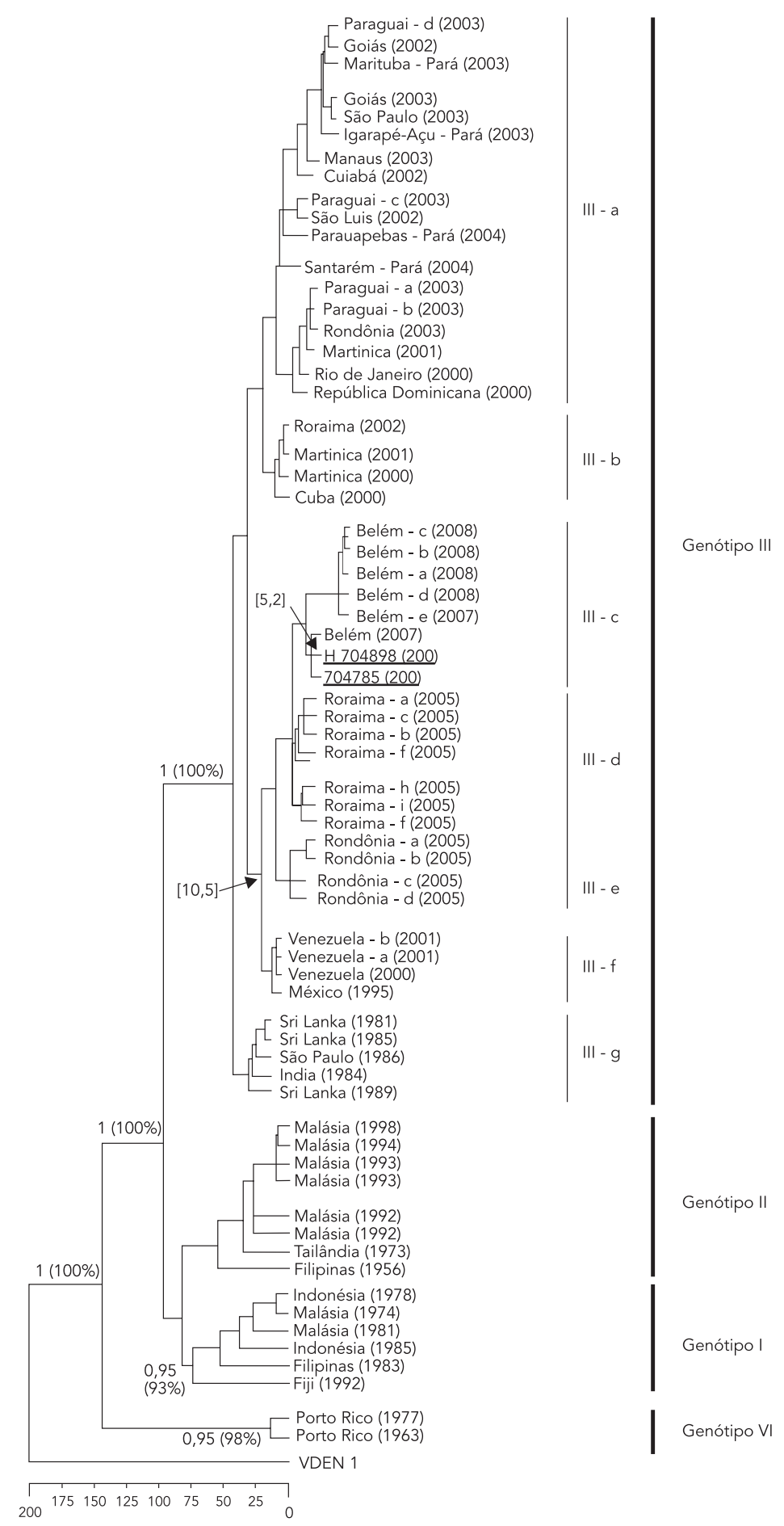

Nota: para efeito comparativo, como a maioria das seqüências para o VDEN-3 não correspondem a seqüências completas do gene E, utilizaram-se seqüências parciais (nucleotídeos 983 a 1783). Valores fora e no interior dos parênteses correspondem aos valores Bayesianos e percentuais de bootstrap. A escala corresponde ao período de emergência calculado com base na taxa de substituição nucleotídica/sítio/ano. 
culicídeos pertencentes aos gêneros Haemagogus, Ochlerotatus e Psorophora também são tidas como importantes transmissoras de arbovírus, principalmente $H$. janthinomys, Ochlerotatus serratus, Psorophora albipes, Psorophora ferox, e diferentes espécies de mosquitos do gênero Sabethes (Sabethes), dos quais, o VFA tem sido isolado 21 . Ademais, outro importante arbovírus, o VMAY (Togaviridae, Alphavirus), tem sido freqüentemente isolado de $H$. janthinomys ${ }^{21}$. Dentre os Ceratopogonidae, o Culicoides paraensis é considerado o principal transmissor do VORO, um orthobunyavírus que causa também uma doença febril aguda não exantemática de grande impacto socioeconômico em regiões tropicais das Américas Central e do Sul, principalmente na região Amazônica brasileira 22,23,24,25,26.

Os flebotomíneos estão amplamente associados à transmissão de flebovírus (Phlebovirus, Bunyaviridae). Esse gênero é composto por 53 flebovírus 27 , dentre os quais, pelo menos, 21 flebovírus foram isolados na Amazônia brasileira entre 1954 e 1994, dos quais, os vírus Candiru, Alenquer, Serra Norte e Morumbi têm sido associados à doença em humanos 15,28.

Em relação aos vertebrados (mamíferos, répteis e aves), os marsupiais (Didelphis marsupialis e Caluromys phylander), roedores (P. guyanensis, Oryzomys goeldi) e edentatas (B. tridactylus e $C$. didactylus) foram os principais mamíferos capturados nas áreas estudadas, dos quais, diferentes arbovírus já foram isolados, tais como membros pertencentes aos gêneros Alphavirus (vírus Pixuna [VPIX]), Flavivirus (VBSQ, VSLE), Orthobunyavirus (VORO, vírus Utinga [VUTG], vírus Macauã [VMAC], VMOJ, vírus Mirim [VMIR], vírus Guajará [VGJR], VCAP, VGMA, vírus Timboteua [VTBA]) e Phlebovirus (vírus Itaituba [VITA], vírus Belterra [VBELT], vírus Bujaru [VBUJ] e vírus Urucuri [VURU]), esses últimos exclusivos de roedores do gênero Proechymis ${ }^{15}$. Arbovírus pertencentes ao grupo Changuinola (vírus Irituia, vírus Jarí e vírus Monte Dourado), bem como rhabdovírus (Rhabdoviridae) pertencentes aos grupos antigênicos Timbó (vírus Timbó, vírus Chaco e vírus Sena Madureira) e Mossuril (vírus Marco) que têm sido exclusivamente associados a répteis, e, no caso dos vírus do grupo Timbó, principalmente à espécie $A$. ameiva 15 . Em relação aos morcegos, as espécies A. literatus e membros do gênero Carollia têm sido associados a isolamentos dos vírus Nepuyo (orthobunyavirus, grupo C) e Tacaribe (arenavírus), bem como ao isolamento do herpesvírus Água preta 15.

No que tange às aves, diversas espécies da área, pertencentes principalmente às ordens Passeriforme e Piciforme, encontram-se associadas com isolamentos de diferentes arbovírus, com destaque para as espécies $R$. carbo (28 espécimes) e Arremon taciturnus (26 espécimes), ambas encontradas tanto em Novo Progresso quanto em Trairão, das quais, os VEEE e os arbovírus VCPC, VGRO, VILH, VITP, VMAY, VORO, VSLE, VTCM, VTUR e VWEE têm sido isolados, respectivamente 29 .

Os resultados sugerem a presença de uma rica biodiversidade animal com uma fauna apresentando diferentes espécies de artrópodes e vertebrados silvestres coexistindo em uma mesma região, o que sugere uma área propícia para a circulação e manutenção de arbovírus.

A prevalência de anticorpos IH para arbovírus, tanto em humanos quanto em animais silvestres (maior prevalência para flavivírus), a ocorrência de reações monotípicas para o VMAY e VORO, presença de reações cruzadas para diferentes orthobunyavírus e alphavírus, além do baixo percentual de anticorpos IgM, sugere que a maioria da população (humana e vertebrados silvestres) não foi recentemente infectada por arbovírus, mas sim em um passado difícil de precisar, indicando que a maioria se encontra suscetível a esses arbovírus. Vale ressaltar, no entanto, que o encontro de anticorpos IgM para os VMAY e VORO indicam infecções recentes. É importante ressaltar que esses arbovírus são associados com epidemias na Amazônia, e é possível que as alterações em curso na área de influência da BR 163 venham a favorecer a dispersão epidêmica desses vírus como já foi previamente documentado na Amazônia 18.

Por outro lado, a análise genética comparativa das cepas do VDEN-3 isoladas em Novo Progresso permitiu um melhor entendimento a respeito da epidemiologia molecular desse agente viral no que tange à dinâmica evolutiva e de dispersão desse vírus na região. Demonstrou-se um padrão heterogêneo de dispersão com a presença de duas portas principais de entrada do VDEN-3 no Brasil entre 2000 e 2008: (i) pela fronteira Brasil-Venezuela, cujas cepas tiveram suas emergências estimadas em 12,1 ( \pm 6) anos, causando epidemias em diferentes estados da Região Norte (Pará, Roraima e Rondônia), incluindo as cepas de Novo Progresso (sul do Estado do Pará), e dispersando-se no sentido Oeste (Rondônia) - Norte (Pará), e (ii) pelas Ilhas Caribenhas, principalmente Cuba, República Dominicana, Martinica e Porto Rico, cuja emergência estimase em, aproximadamente, 11,2 ( \pm 5 ), com dispersão múltipla originando-se na Região Sudeste, no Estado do Rio de Janeiro 30,31,32, em direção a diferentes localidades das regiões Centro-Oeste, Nordeste e Norte e países vizinhos do Cone Sul (Figura 2). 
Em termos gerais, os dados obtidos (fauna, sorologia e biologia molecular) sugerem que a população da área em estudo encontra-se pouco imunizada para arbovírus, o que requer um apropriado manejo do ambiente e medidas de prevenção e controle, na tentativa de evitar a emergência de arbovírus que possam acarretar graves problemas de saúde pública e sócio-econômicos para a região, o que pode vir a ocorrer com a pavimentação da BR 163. Portanto, é importante um monitoramento dinâmico das populações locais e de imigrantes quanto à presença de anticorpos para arbovírus, o que permitirá um efetivo controle das infecções por esses agentes virais nas populações residentes na área da rodovia dentro do território paraense.

\section{Resumo}

O presente estudo descreve os aspectos eco-epidemiológicos sobre arbovírus nos Municípios de Novo Progresso e Trairão, Estado do Pará, Brasil, na área de influência da BR 163. Anticorpos IH foram detectados para diferentes arbovírus, com reações monotípicas para os VMAY e VORO, dois importantes arbovírus associados a epidemias na Amazônia. Anticorpos IgM para o VORO e VMAY foram detectados em soros humanos, sugerindo infecção recente por esses arbovírus. Duas cepas do VDEN-3 foram isoladas de pacientes febris residentes em Novo Progresso e identificadas como genótipo III. Em termos gerais, os dados obtidos suge- rem uma área propícia para a circulação e manutenção de arbovírus e uma população pouco imunizada. Portanto, é importante um monitoramento dinâmico das populações locais e de imigrantes e de animais silvestres quanto à presença de anticorpos e isolamentos de arbovírus, o que permitirá um efetivo controle das infecções por esses agentes virais em residentes da área da rodovia dentro do território paraense.

Monitoramento Ambiental; Vetores de Doenças; Arbovírus; Surtos de Doenças; Doenças Transmissíveis 


\section{Colaboradores}

M. R. T. Nunes participou da concepção do projeto amplificação do genoma de arbovírus, do seqüenciamento nucleotídico, da análise dos dados e elaboração do artigo. T. F. S. Barbosa e L. M. N. Casseb analisaram os dados referentes aos morcegos, revisaram criticamente e aprovaram a versão final para publicação. J. P. Nunes Neto e N. O. Segura contribuíram com a análise dos dados referentes à captura de artrópodes hematófagos nas áreas estudadas, revisão crítica e aprovação da versão final para publicação. H. A. O. Monteiro realizou a análise dos dados referentes à classificação entomológica dos espécimes de artrópodes capturados e participou da elaboração do artigo, revisão crítica do manuscrito e aprovação da versão final para publicação. E. V. Pinto participou da análise dos dados referentes ao isolamento viral, da revisão crítica do artigo e aprovação da versão final para publicação. S. M. Casseb contribuiu com a análise dos dados genéticos (seqüenciamento nucleotídico), revisão crítica e aprovação da versão final para publicação. J. O. Chiang participou da análise dos dados referentes à detecção de anticorpos IgM para arbovírus, da revisão crítica e aprovação da versão final para publicação. L. C. Martins participou da análise e interpretação dos dados referentes a testes sorológicos, detecção de anticorpos IH para arbovírus, revisão crítica e aprovação da versão final para publicação. D. B. A. Medeiros analisou os dados referentes à amplificação e ao seqüenciamento do genoma de arbovírus e participou da elaboração do artigo, revisão crítica e aprovação da versão final. P. F. C. Vasconcelos contribuiu com a concepção do projeto, análise e interpretação dos dados clínico-epidemiológicos, redação do artigo, revisão crítica e aprovação da versão final para publicação.

\section{Agradecimentos}

A coordenação do projeto BR 163 na área de abrangência do Estado do Pará agradece aos técnicos Osvaldo Vaz da Silva, Orlando Vaz da Silva, Basílio Buna Silva, Elpidia, Ercilia, Maxuwel Furtado de Lima, Mario Ferro e Maria pelo apoio técnico de trabalho de campo no que tange à captura de animais e artrópodes de campo, coleta de amostras para sorologia, tentativa de isolamento viral e detecção do genoma viral.

\section{Referências}

1. Soares Filho B, Alencar A, Nesptad D, Cerqueira G, Diaz MDV, Rivero S, et al. Simulation the response of land-cover changes to the roads paving and governace along a major highways: the SantaremCuiaba corridor. Glob Chang Biol 2004; 10:745-64.

2. Nepstad D, Carvalho G, Barros AC, Alencar A, Capobiaco JP, Bishop J, et al. Road paving, fire regime feedbacks, and future of Amazon forests. For Ecol Manage 2001; 154:395-407.

3. Roselem R. O impacto do desmatamento no ciclo hidrológico: um estudo de caso para a rodovia Cuiabá-Santarém [Dissertação de Mestrado]. Piracicaba: Escola Superior de Agricultura, Universidade de São Paulo Luiz de Queiroz; 2005.

4. Ministério do Meio Ambiente. O Brasil e a conservação da Floresta Amazônica. InforMMA Especial 2006; jan.

5. Beaty BJ, Calisher CH, Shope RE. Arboviruses. In: Schmidt NJ, Emmons RW, editors. Diagnostic procedure for viral, rickettsial and chlamydial infections. $6^{\text {th }}$ Ed. Washington DC: American Public Health Association; 1989. p. 795-855.
6. Clarke DH, Casals J. Technique for hemagglutination and hemagglutination inhibition with arthropod-borne viruses. Am J Trop Med Hyg 1958; 7:561-73.

7. Shope RE. The use of a microhemagglutinationinhibition test to follow antibody response after arthropod-borne virus infection in a community of forest animals. An Microbiol (Rio J.) 1963; 11: 167-71.

8. Kuno G, Gomez J, Gubler DJ. Detecting artificial antidengue IgM immune complexes using an enzymelinked immunosorbent assay. Am J Trop Med Hyg 1987; 36:153-9.

9. Vasconcelos PFC, Travassos-da-Rosa JFS, Rodrigues SC, Dégallier N, Travassos-da-Rosa APA Primeiro registro de epidemias causadas pelo vírus Oropouche nos estados do Maranhão e Goiás, Brasil. Rev Inst Med Trop São Paulo 1989; 4:271-8. 
10. Lanciotti RS, Calisher CH, Gubler DJ, Chang GJ, Vorndam AV. Rapid detection and typing of dengue viruses from clinical samples by using reverse transcriptase-polymerase chain reaction. J Clin Microbiol 1992; 30:545-51.

11. Sanger F, Nicklen S, Coulson AR. DNA sequencing with chain-terminating inhibitors. Proc Natl Acad Sci USA 1977; 74:5463-7.

12. Drummond AJ, Ho SYW, Phillips MJ, Rambaut A. Relaxed phylogenetics and dating with confidence. PLoS Biol 2006; 4:e88.

13. Jenkins GMR. Rates of molecular evolution in RNA viruses: A quantitative phylogenetic analysis. J Mol Evol 2002; 54:156-65.

14. Travassos-da-Rosa APA, Travassos-da-Rosa JFS, Pinheiro FP, Vasconcelos PFC. Arboviroses. In: Leão RNQ, organizador. Doenças infecciosas e parasitárias - enfoque Amazônico. Belém: Editora Cejup/Universidade do Estado do Pará/Instituto Evandro Chagas; 1997. p. 207-25.

15. Travassos-da-Rosa JFS, Travassos-da-Rosa APA, Vasconcelos PFC, Pinheiro FP, Rodrigues SG, Travassos-da-Rosa ES, et al. Arboviruses isolated in Evandro Chagas Institute, including some described for the first time in the Brazilian Amazon Region, their known hosts, and their pathology for man. In: Travassos-da-Rosa APA, Vasconcelos PFC, Travassos-da-Rosa JFS, organizadores. An overview of Arbovirology in Brazil and neighbouring countries. Gráfica e Editora Santo Antônio: 1998. p. 19-31.

16. Martins LC, Diniz JAP, Silva EVP, Barros VLRS, Monteiro HAO, Azevedo RSS, et al. Characterization of Minaçu virus (Reoviridae: Orbivirus) and pathological changes in experimentally infected newborn mice. Int J Exp Pathol 2007; 88:63-73.

17. Vasconcelos PFC, Travassos-da-Rosa APA, Degallier N, Travassos-da-Rosa JFS, Pinheiro FP. Clinical and ecoepidemiological situation of human arboviruses in Brasilian Amazon. Ciênc Cult 1992; 44:117-24.

18. Vasconcelos PFC, Travassos-da-Rosa APA, Rodrigues SG, Travassos-da-Rosa ES, Monteiro HAO, Cruz ACR, et al. Yellow fever in Pará State, Amazon region of Brazil, 1998-1999. Entomological and epidemiological findings. Emerg Infect Dis 2001; 7:565-9.

19. Pinheiro FP, Travassos-da-Rosa APA, Vasconcelos PFC. Arboviroses. In: Veronesi R, Foccacia R, organizadores. Tratado de infectologia. São Paulo: Editora Ateneu; 1997. p. 169-80.

20. Vasconcelos PFC, Travassos-da-Rosa APA, Hervé JP, Travassos-da-Rosa JFS. Febre amarela silvestre no Estado do Pará, Brasil, 1984. Inf Epidemiol SUS 1984; 16:97-104.

21. Travassos-da-Rosa APA, Travassos-da Rosa ES, Travassos-da-Rosa JFS, Dégallier N, Vasconcelos PFC, Rodrigues SG, et al. Os arbovírus no Brasil: generalidades, métodos e técnicas de estudo. Belém: Instituto Evandro Chagas; 1994. (Documento Técnico, 1994).
22. Pinheiro FP, Travassos-da-Rosa APA, Vasconcelos PFC. Oropouche fever. In: Feigin RD, Demmler GJ, Kaplan SL, editors. Textbook of pediatric infectious diseases. $5^{\text {th }}$ Ed. Philadelphia: Saunders; 2004. p. 2418-23.

23. Nunes MRT, Martins LC, Rodrigues SG, Chiang JO, Azevedo RSS, Travassos-da-Rosa APA, et al. Oropouche virus isolation, Southeast Brazil. Emerg Infect Dis 2005; 11:1610-3.

24. Azevedo RSS, Nunes MRT, Chiang JO, Bensabath G, Vasconcelos HB, Pinto AYN, et al. Reemergence of Oropouche fever in Northern Brazil. Emerg Infect Dis 2007; 13:912-5.

25. Nunes MRT, Vasconcelos HB, Medeiros DBA. Rodrigues SG, Azevedo RSS, Chiang JO, et al. A febre do Oropouche: uma revisão dos aspectos epidemiológicos e moleculares na Amazônia Brasileira. Cad Saúde Colet 2007; 15:303-18.

26. Vasconcelos HB, Azevedo RSS, Casseb NunesNeto JP, Chiang JO, Cantuária PC, Segura MNO, et al. Oropouche fever epidemic in Northern Brazil: epidemiology and molecular characterization of isolates. J Clin Virol 2009; 44:129-33.

27. Fauquet CM, Mayo M, Maniloff J, Desselberger U, Ball LA. Virus taxonomy classification and nomenclature of viruses. $8^{\text {th }}$ Ed. San Diego: Elsevier Academic Press; 2005.

28. Rodrigues SG, Travassos-da-Rosa APA, Vasconcelos PFC, Tesh RB, Travassos-da-Rosa JFS. Characterization of two new phleboviruses associated with human illness from the Amazon region of Brazil. In: Travassos-da-Rosa APA, Vasconcelos PFC, Travassos-da-Rosa JFS, organizadores. An overview of arbovirology in Brazil and neighbouring countries. Belém: Gráfica e Editora Santo Antônio; 1998. p. 100-5.

29. Nicolas D, Travassos-da-Rosa APA, Silva JMC, Rodrigues SG, Vasconcelos PFC, Travassos-da-Rosa JFS, et al. As aves como hospedeiras de arbovírus na Amazônia Brasileira. Bol Mus Para Emilio Goeldi, Zool 1992; 8:69-111.

30. Nogueira RMR, Miagostovich MP, Filippis AMB, Pereira MAS, Schatzmayr HG. Dengue virus type 3 in Rio de Janeiro, Brazil. Mem Instituto Oswaldo Cruz 2001; 96:925-6.

31. Aquino VH, Anatriello E, Gonçalves PF, Silva EV, Vasconcelos PF, Vieira DS, et al. Molecular epidemiology of dengue type 3 virus in Brazil and Paraguay, 2002-2004. Am J Trop Med Hyg 2006; 75:710-5.

32. Aquino JD, Tang WF, Ishii R, Ono T, Eshita Y, Aono H, et al. Molecular epidemiology of dengue virus serotypes 2 and 3 in Paraguay during 2001-2006: the association of viral clade introductions with shifting serotype dominance. Virus Res 2008; 137:26670.

Recebido em 10/Fev/2009

Versão final reapresentada em 14/Jul/2009

Aprovada em 20/Jul/2009 